\title{
DE VOORSTELLING VAN LEASING-CONTRACTEN \\ IN DE JAARREKENING
}

\author{
door Drs. K. Kruisbrink
}

\section{Inleiding}

Het verkrijgen van beschikkingsmacht over kapitaalgoederen door middel van huur is bepaald geen nieuw verschijnsel. Na de tweede oorlog ontwikkelde zich echter - met name in de Angelsaksische landen - een specifieke vorm van huurcontracten, verder aan te duiden met de term ,leasing”, met een zodanig eigen karakter, dat deze financieringsfiguur de aandacht trok van bedrijfseconomen en accountants.

Deze belangstelling betrof enerzijds de betekenis van deze partiële financiering in het gehele financieringsplan van de onderneming en daarnaast de vraag, of in de jaarrekening op enigerlei wijze van het bestaan van deze leasing-contracten zou moeten blijken.

Tussen beiden bestaat verband: de balans dient een zo goed mogelijk beeld te geven van de vermogensstructuur, dat is van de toegepaste financiering en men kan zich afvragen of het balansbeeld wel een juist inzicht geeft, indien daaruit niet van het bestaan van relatief van betekenis zijnde leasing-contracten zou blijken.

Hoewel de vraagstelling al een bevestigende beantwoording suggereert, schuilen hier toch wel enkele complicaties.

De vraag rijst immers aanstonds waarom deze problematiek al niet is opgeworpen ten aanzien van de reeds langer voorkomende ,normale" huur van duurzame activa.

In Nederland is dit onderwerp aan de orde geweest in het rapport van de Commissie van Advies inzake Beroepsaangelegenheden (van het Nederlands Instituut van Accountants) betreffende het al dan niet verwerken van obligo's in de verslaglegging, gepubliceerd in 1956.

In dit rapport werd o.m. aandacht geschonken aan de obligo's voortvloeiende uit huurkoopcontracten en zgn. langdurige huurcontracten.

Met betrekking tot de huurkoopcontracten werd in genoemd rapport geconcludeerd, dat de invloed op het vermogen en op het resultaat van de uit huurkoopcontracten voortvloeiende obligo's het nuttig en naar gelang van de relatieve omvang zelfs noodzakelijk maakte hiervan in de verslaglegging van de hurende onderneming melding te maken.

Ten aanzien van de zgn. langdurige huurcontracten werd in het rapport opgemerkt, dat het kan voorkomen, dat een langdurig huurcontract, wat structuur betreft, het koopcontract dicht nadert. Als voorbeeld wordt genoemd het geval van de onderneming, die een gebouw voor 20 jaar huurt tegen een huursom, die praktisch een volledige vergoeding voor bouwkosten, interest e.d. inhoudt.

De voorzichtige conclusie die naar aanleiding hiervan werd getrokken, was dat men zich er rekenschap van zal moeten geven of onder andere in de duur van het huurcontract en de hoogte van de huursom bijzondere elementen schuilen en zo ja, welke consequenties voor de vermelding in het jaarverslag daaraan zijn verbonden.

Tot zover enkele aanhalingen uit het eerdergenoemde rapport van de C.A.B. 
Een meer recente en ook stelliger uitspraak omtrent dit vraagstuk is te vinden in het Rapport van de Commissie Verdam van 1965.

Artikel 22 van het in dit rapport opgenomen voorontwerp van een wet op de jaarrekening van ondernemingen luidt als volgt.

"Indien de onderneming zich heeft verbonden tot de voldoening van voor haar belangrijke financiële verplichtingen gedurende een aantal jaren, zoals tengevolge van erfpacht, opstal, huur, pacht, koop op afbetaling ... wordt van deze verplich. tingen, hetzij onder de schulden, hetzij afzonderlijk melding gemaakt."

Tot zover en dit ter inleiding enkele Nederlandse uitspraken, dic in verband kunnen worden gebracht met het vraagstuk van de voorstelling van leasing-contracten in de jaarrekening. Nog opgemerkt zij, dat - ook in het rapport Verdam niet wordt ingegaan op de meest doelmatige wijze waarop de betreffende gegevens behoren te worden vermeld.

Het rapport van de C.A.B. noemt wel enkele mogelijkheden (in de balans - eventueel binnenslijns -, onder de balanstelling, als noot bij de balans of in de toelichting) doch meent, dat men zich van geval tot geval zal moeten afvragen, welke wijze van vermelden het duidelijkst is.

\section{Historisch overzicht van Amerikaanse opvattingen}

De cerste bemoeiingen van het Amerikaanse instituut van Accountants dateren uit 1949 toen de Commissie „on accounting procedure” het 38 ste accounting research bulletin het licht deed zien.

Hierin wordt erop gewezen, dat het niet gebruikelijk is, dat ondernemingen die gebouwen e.d. huren van het bestaan van deze huurcontracten of van de hoogte van de jaarlijkse huurtermijnen melding maken in de jaarrekening, doch dat de toeneming van de huurcontracten op lange termijn voor vaste activa, als substituut voor eigen aankoop door middel van een (hypothecaire) lening, de vraag oproept hoe zulks in het jaarverslag tot uitdrukking dient te worden gebracht.

Het desbetreffende bulletin werd vrijwel ongewijzigd opnieuw in 1953 uitgegeven (accounting research bulletin 43).

De twee voornaamste hierin opgenomen aanbevelingen waren, dat omtrent belangrijke langlopende contracten in het jaarverslag de jaarlijkse huurtermijn en de contractsperiode vermeld dienden te worden. Voorts, dat indien de transactie in wezen als een koop van het desbetreffende actief zou zijn aan te merken, opneming hiervan in de overeenkomstige rubriek van vaste activa in de jaarrekening aanbeveling zou verdienen.

Hoewel de publikatie van 1953 ertoe leidde, dat de informatie omtrent leasingcontracten in de jaarverslaggeving enige uitbreiding onderging, bleef de situatic nochtans vrij onduidelijk.

Het kwam slechts zelden voor, dat de gehuurde produktiemiddelen gekapitaliseerd in de balans werden opgenomen. Dit wees er wel op, dat nog onvoldoende duidelijk was aangegeven, welk criterium beslissend was voor de beantwoording van de vraag wanneer ,a lease is in substance a purchase".

Dientengevolge werd het vraagstuk opnieuw in studie genomen, thans door het „accounting researchbureau". In mei 1962 werd gepubliceerd de Accounting research study nr. 4.

In deze studie werd het criterium voor relevante, d.w.z. afzonderlijk in de 
balans op te nemen leasing-contracten, gezocht in het verkrijgen van zgn. ,property rights". Bepalend zou dus zijn de vraag of de huurder zich kan gedragen als degene, die de eigendomsrechten over het gehuurde object uitoefent.

Het rapport van het accounting researchbureau was voor de Accounting Principles Board aanleiding inzake dit onderwerp een „Opinion” (nr. 5) te publiceren.

$\mathrm{Na}$ zorguuldige overweging concludeerde de A.P.B. in feite tot een verwerping van de aanbevelingen van het accounting researchbureau, in die zin, dat niet het ontstaan van formele "property rights" als beslissend werd beschouwd, doch de voorkeur werd gegeven aan de - nader te omschrijven - economische kenmerken van het contract.

Het is deze Opinion nr. 5, die in de Inventory of gencrally accepted accounting principles is afgedrukt en in het volgende nader zal worden besproken.

\section{Economisch karakteristick van leasing-contracten}

Volgens de Accounting Principles Board gaat het om de beginselvraag of en in hoeverre door leasing-contracten, die wel de gebruiksrechten van een goed verschaffen doch niet de eigendom daarvan, activa en passiva in het leven worden geroepen, die tezamen met de overige activa en passiva in de balans behoren te worden vermeld.

Ruimer gesteld betreft het de vraag, of in het algemeen rechten en verplichtingen die uit overeenkomsten voortvloeien in de balans tot uitdrukking behoren te worden gebracht.

De A.P.B. rekent het echter niet tot goed koopmansgebruik om rechten en verplichtingen uit nog niet geheel ten uitvoer gebrachte overeenkomsten al in de balans tot uitdrukking te brengen. Alleen in die gevallen waar het achterwege laten van informatie dienaangaande het beeld van de jaarrekening misleidend zou maken, is vermelding ervan, bij voorkeur door middel van een aanvullende toelichting of een voetnoot bij de balans, geboden.

Dit geldt volgens de A.P.B. óók voor belangrijke huurcontracten; wat de eigenlijke leasing-contracten betreft meent de A.P.B. echter dat een uitzondering moet worden gemakt $\mathrm{nl}$. in die gevallen waarin het leasing-contract in wezen gelijk te stellen is aan het geval van en koop op afbetaling.

Het leasing-contract zal dan naar het oordeel van de A.P.B. de volgende kenmerken moeten dragen.

- het contract kan niet worden geannuleerd, of wel kan alléén worden geannuleerd op grond van zeer bijzondere voorshands niet te verwachten omstandigheden.

- de eerste periode van het huurcontract is belangrijk korter dan de (economische) levensduur van het object, terwijl de huurder het recht heeft om de huur te verIengen voor de resterende levensduur, en wel tegen een huurprijs die beneden de normale huurwaarde ligt.

- de huurder heeft het recht om tijdens of eventueel aan het einde van de contractsperiode het gehuurde te verwerven tegen een prijs, die althans beoordeeld naar de omstandigheden aan het begin van de contractsperiode, aanmerkelijk lager is dan de vermoedelijke bedrijfswaarde op het tijdstip van de eventuele overdracht.

De omstandigheid, dat de periodieke huurbedragen in de eerste periode uitgaan boven de jaarlijkse waardevermindering van het object, tezamen met de mogelijk. heid voor de huurder om na verloop van tijd het huurcontract te verlengen tegen 
een lagere huurprijs of eventueel tegen een lage prijs te kopen, betekent volgens de A.P.B. dat hier door middel van de huurbetalingen een eigen vermogen groeit, waardoor de gehele transactic in wezen gelijk te stellen is aan een koopovereenkomst.

Hoewel in het voorgaande de meest kenmerkende eigenschappen van de categorie leasing-contracten zijn aangeduid, kunnen daarnaast nog enkele secundaire kenmerken worden genoemd, t.w.

- het verhuurde produktiemiddel werd door de verhuurder aangekocht om aan de specifieke behoeften van de huurder te kunnen voldoen en zal naar alle waarschijnlijkheid ook alleen door de desbetreffende huurder worden gehuurd en gebruikt.

- de totale duur van het huurcontract correspondeert vrijwel met de economische levensduur van het object en de huurder is verplicht om de kosten verbonden aan het verbruik te betalen, zoals de kosten van verzekering en onderhoud alsmede zakelijke belastingen.

- de huurder heeft de verplichtingen gegarandeerd, die de verhuurder ten aanzien van het verhuurde object op zich heeft genomen.

- de huurder gedraagt zich in fiscaal opzicht alsof hij de koper in plaats van de huurder was.

- tenslotte zal ook het bestaan van een bepaalde relatie tussen huurder en verhuurder (b.v. door middel van onderling aandelenbezit) erop kunnen wijzen, dat het leasing-contract naar zijn aard een koopovereenkomst is.

In het voorgaande zijn de .- naar het oordeel van de A.P.B. - bijzondere kenmerken aangegeven waaraan leasing-contracten moeten voldoen, zo men deze in economisch opzicht gelijk wil stellen aan koopcontracten en verwerking ervan in de jaarrekening nodig is te achten. In afwijking derhalve van het standpunt van accounting research acht de A.P.B. dit laatste derhalve niet voor alle leasingcontracten noodzakelijk.

\section{De wijze van voorstelling in de jaarrekening}

De A.P.B. doet ten aanzien van de met koop op termijn gelijk te stellen leasing transacties de volgende aanbevelingen.

Het desbetreffende produktiemiddel alsmede de daarmede samenhangende betalingsverplichting behoren in de balans te worden verwerkt. De waardering van het actief dient te geschieden tegen de contante waarde van de, ingevolge het leasing-contract verschuldigde huurbedragen.

In een afzonderlijke toelichting of voetnoot bij de balans zullen nadere bijzonderheden met betrekking tot de leasing-overeenkomst behoren te worden verineld; te denken valt aan de huurbedragen, de duur van het contract en eventuele andere bijzonderheden.

Ten aanzien van de leasing-contracten, die op grond van hetgeen in $\$ 3$ werd uiteengezet niet gelijk gesteld worden aan een koopovereenkomst, doch overigens wel van voldoende betekenis zijn om er van melding te maken zal volgens de A.P.B. kapitalisatie in de balans geen aanbeveling verdienen en volstaan kunnen worden met een afzonderlijke toelichting, vermeldende de voornaamste bijzonderheden van het contract. 
Kort samengevat luidt derhalve de aanbeveling van de A.P.B.: „disclose rental charges under material leases and capitalize those which are in effect installment purchases of fixed assets".

Ten behoeve van het opnemen van de gekapitaliseerde waarde van de gehuurde activa in de balans, zal men het deel van de huurprijs moeten kennen, dat geacht kan worden een element van de aankoopprijs te vormen. De bijzondere kosten zullen derhalve mocten worden uitgeschakeld. Vervolgens zal de rentevoet waartegen de kapitalisatie plaatsvindt moeten worden bepaald.

In het algemeen zal het wenselijk zijn de gekapitaliseerde waarde van de desbetreffende activa wel in de rubriek van de duurzame activa maar dan afzonderlijk op te nemen.

Wat betreft de resultatenrekening, valt de huurprijs uiteen in een afschrijvingsgedeelte en een deel interest. De mogelijkheid is niet uitgesloten, dat de economische slijtage van het produktiemiddel een zodanig snel verloop heeft, dat het afschrijvingsbedrag dat ten laste van de resultatenrekening wordt gebracht, althans in de eerste tijd groter is dan de jaarlijkse huurtermijnen en eerst na verloop van tijd daar beneden komt te liggen.

Tegen de aanbeveling tot kapitalisatie in de balans van leasing-contracten is in Amerika van verschillende zijden bezwaren gemaakt. Ook één van de leden van de A.P.B. bleek zich ten aanzien van dit punt niet met de opinie van de overige leden te kunnen verenigen.

Het is illustratief enkele van de geuite bezwaren hier te releveren.

Een eerste bezwaar is van formeel-juridische aard, in die zin, dat het onjuist wordt geacht de rechten uit een leasing-contract voortvloeiende, gelijk te stellen aan de eigendom van de activa. De balansprestatie zou daarom onjuist zijn, als dit onderscheid niet tot uitdrukking zou komen.

Het tweede bezwaar richt zich tegen de subjectieve schattingen, die noodzakelijk zijn om de leasing-contracten te kunnen kapitaliseren, o.a. de schatting van het deel van de huur, dat op de onderhoudskosten betrekking heeft en de bepaling van de rentevoet.

Deze categorie bezwaren is door de A.P.B. niet aanvaard. Bepaalde schattingen zijn bij iedere balanswaardering noodzakelijk en onvermijdelijk.

Van andere aard is het bezwaar, dat men pas tot kapitalisatie van leasingcontracten in de balans zou mogen besluiten, indien ook reeds een standpunt zou zijn ingenomen ten aanzien van de verwerking in de jaarrekening van andere lopende contracten en verplichtingen.

Belangwekkender is een vierde bezwaar dat naar voren wordt gebracht en waarbij gewezen wordt op de economische gevolgen van kapitalisatie in de balans. De gebruikelijke - met name in de U.S.A. veel voorkomende - kengetallen en verhoudingscijfers, gehanteerd door financiële deskundigen en beleggingsspecialisten zouden door de kapitalisatie geheel afwijkende uitkomsten kunnen geven. Hierdoor zouden in de loop der tijd gegroeide normcijfers worden aangetast en zou verwarring ontstaan.

Uiteraard is deze argumentatie weinig zinvol. Indien men na zorgvuldige overweging tot de conclusie is gekomen, dat kapitalisatie van leasing-contracten in de balans aanbeveling verdient, dan is zulks juist omdát men van oordeel is, dat het 
inzicht in de vermogensstructuur en de methode van financiering daardoor wordt verbeterd. De financiële kengetallen zullen dan moeten worden aangepast.

Van dezelfde aard is de stelling, dat de aantrekkelijkheid van leasing, die wordt gezien in de mogelijkheid tot het ,schoonhouden" van de balans teloor zou gaan, indien de kapitalisatie verplicht zou worden.

Het zijn bezwaren die vooral geuit worden van de zijde van banken en andere financieringsmaatschappijen. Men komt dan uitspraken tegen als de volgende: "Capitalization strikes at the very foundation of accounting" en "the standard wording of the auditor's certificate could become mockery and the task of the financial analyst almost impossible."

In een artikel in het Journal of accountancy van juli 1963 getiteld „Capitalisation leases - the effect on financial ratios" heeft A. T. Nelson het vraagstuk van de balanspresentatie nader geanalyseerd. Dit geschiedde aan de hand van de balanscijfers van een elftal ondernemingen, waarvan de zeven zgn. „major ratio's” werden berekend, zowel vóór als ná kapitalisatie van de leasing-contracten.

Opgemerkt zij, dat tot de zeven major ratio's de volgende verhoudingscijfers werden gerekend:

- verhouding tussen vlottende activa en schulden op korte termijn (current ratio).

- vreemd vermogen ten opzichte van eigen vermogen.

- vreemd vermogen t.o.v. totaal geïnvesteerd vermogen.

- rentabiliteit van het totale geïnvesteerde vermogen.

- aantal malen, dat de rentelast wordt verdiend.

- vreemd vermogen op lange termijn t.o.v. in vaste activa geïnvesteerd vermogen.

- vaste activa t.o.v. het totale in materiële activa geïnvesteerde vermogen.

Zoals te verwachten viel, was de conclusie, dat de verschillende ratio's onmiskenbare verschuivingen ondergaan, indien kapitalisatie van leasing-contracten plaatsvindt. Juist om dié reden bevatte het artikel een krachtig pleidooi voor de opvattingen van de A.P.B.; de genoemde ratio's zouden een realistischer en daarom betrouwbaarder beeld geven.

\section{Leasing-contracten in de jaarrekening van de verbuurder}

Het vraagstuk van de voorstelling van leasing-contracten in de jaarrekening van de verhuurder $\mathrm{kreeg}$ in het algemeen veel minder aandacht.

Een reden hiervoor is dat el slechts weinig ondernemingen zijn waar de verhuurde objecten een belangrijk deel uitmaken van de totale investeringen. Nochtans blijft de vraag in hoeverre de verhuurde activa als beleggingsobject of als produktiemiddel moeten worden aangemerkt.

Voorts is er het vraagstuk van de methode van resultatenbepaling.

In de eerdergenoemde Opinion nr. 5 van de A.P.B. wordt aan deze problematiek geen afzonderlijke aandacht geschonken. Wél was dit het geval in Research study nr. 4 betreffende „Reporting of leases in financial statements”.

In dit rapport worden twee methoden van resultaten verantwoording beschreven.

Volgens de ene (de „rental method") wordt de „huur” opbrengst geheel als bate genomen in het jaar waarin zij wordt ontvangen. Hiertegenover staan dan de 
kosten van het verhuurde object, waaronder te rekenen zijn de onderhoudskosten, alsmede de afschrijvingen en rente.

De andere methode (de finance method) is die, waarbij men de transactie beschouwt als een verkoop op afbetaling. In dat geval wordt de contante waarde van de totale vordering geboekt, waartegenover de grootboekrekening duurzame activa - behoudens een eventueel nog te verrekenen restwaarde - wordt gecrediteerd.

Veelal wordt de winst dan genomen naarmate de betalingen op de vordering binnenkomen.

\section{Sale and lease back}

Wanneer het huurcontract wordt gesloten na een daaraan voorafgaande transactie, waarbij de huurder het object aan de verhuurder heeft verkocht, is het duidelijk, dat deze transacties met elkaar samenhangen en dienen beide contracten in hun onderling verband te worden beoordeeld.

Naar de mening van de A.P.B. behoren de winsten of verliezen ontstaan uit de verkoop te worden verdeeld over de duur van het huurcontract, bij wijze van correctic op de overeengekomen huurprijs, of indien het leasing-contract wordt gekapitaliseerd als een correctie op het bedrag van de afschrijving.

7 Het geheel overziende moet worden geconcludeerd, dat door de Accounting Principles Board een nuttige bijdrage is geleverd met betrekking tot het vraagstuk van de meest doelmatige presentatie van de jaarrekening. Ervan uitgaande, dat het doel van de balans is een duidelijk beeld te geven van de grootte en de samenstelling van het vermogen en van de kapitaalscomponenten waarin dit vermogen is geinvesteerd, moet worden erkend, dat verbintenissen uit leasing-contracten in bepaalde gevallen in de jaarrekening zullen moeten worden verwerkt.

Door middel van de gekapitaliseerde waarde van de desbetreffende verbintenissen als afzonderlijke post in de balans zal zulks het best tot uitdrukking kunnen worden gebracht.

De alternatieve presentatie: als voetnoot bij de balans, of ergens in de toelichting daarop, is minder duidelijk en dientengevolge niet gelijkwaardig te beschouwen. 